\title{
Cross Effect of Exercise, Gender and Level of Sport Expertise on Cognition: Visual Perception, Information Processing and Motor Response
}

\author{
Imane El Moutaraji ${ }^{1, *}$, Said Lotfi ${ }^{2}$, Mohammed Talbi ${ }^{1}$ \\ ${ }^{1}$ Observatory of Research in Didactics and University Pedagogy (ORDIPU), Laboratory of Physical Chemistry of Materials, Faculty \\ of Sciences Ben M' Sik, Casablanca, Morocco, University Hassan II, Casablanca, Morocco \\ ${ }^{2}$ Sport Science Assessment and Physical Activity Didactics, Multidisciplinary Laboratory in Education Sciences and Training \\ Engeneering (LMSEIF), Normal Superior School (ENS), University Hassan II, Casablanca, Morocco
}

Received January 20, 2021; Revised March 22, 2021; Accepted April 18, 2021

\section{Cite This Paper in the following Citation Styles}

(a): [1] Imane El Moutaraji, Said Lotfi, Mohammed Talbi, "Cross Effect of Exercise, Gender and Level of Sport Expertise on Cognition: Visual Perception, Information Processing and Motor Response," International Journal of Human Movement and Sports Sciences, Vol. 9, No. 3, pp. 412 - 420, 2021. DOI: 10.13189/saj.2021.090304.

(b): Imane El Moutaraji, Said Lotfi, Mohammed Talbi (2021). Cross Effect of Exercise, Gender and Level of Sport Expertise on Cognition: Visual Perception, Information Processing and Motor Response. International Journal of Human Movement and Sports Sciences, 9(3), 412 - 420. DOI: 10.13189/saj.2021.090304.

Copyright $\mathrm{C} 2021$ by authors, all rights reserved. Authors agree that this article remains permanently open access under the terms of the Creative Commons Attribution License 4.0 International License

\begin{abstract}
To address several recommendations proposing to cross the impact of different variables on cognitive performance, the objective of this study first is to examine the impact of physical exercise variables on cognitive tasks (visual perception, information processing and motor response) at different level of training. The study was carried out on a sample of 88 participants (experts: $n=$ 29, advanced: $\mathrm{n}=30$, novices, $\mathrm{n}=29$ ) performed the coding decoding test, search symbol and the lead psychomotor tester, in order to assess the variations of cognitive profile, at rest and after bout of handball exercise. The results showed, a higher level of training corresponds to a higher level in visual perception with $301 \mathrm{~ms}$, motor reaction time with $170 \mathrm{~ms}$ and choice reaction time with $472 \mathrm{~ms}$ for the expert's group, although novices have a greater range of improvement following the exercise with a respective improvement of $33 \%$ and $20.20 \%$ in search symbol and coding decoding and a respective decrease in visual perception time, motor response and choice reaction time by $16.18 \%, 14.42 \%$ and $14.10 \%$. Also, the combination of the level of training and exercise attenuates differences on some sensorimotor speed performance between the two sexes. The cross effect affects positively but selectively on certain cognitive functions. Our findings enlighten the sport cognition relationship and suggest using physical and sport activity as a means of stimulating
\end{abstract}

cognitive skills and student development in school and university training programs.

Keywords Cognition, Exercise, Visual Perception, Information Processing, Motor Reaction

\section{Introduction}

For several years, a number of studies have focused on the interaction between acute physical exercise and cognitive performance, as reported in Tomporowski's meta-analysis [1]. The results of these studies have revealed some contradictions. Some showed significantly positive results while others reported a deterioration effect and some reported no effect [2-5].Before going further in our study, we adopt the definition of exercise of Dishman and his co-authors who define exercise as a "subset of physical activities consisting of planned, structured and repetitive body movements with the aim of improving or maintaining one or more components of physical condition or health" (Dishman, Washburn and Heath, 2004). As for cognition, it is defined as the set of processes that allow the processing of information and the construction of knowledge. These processes are called "cognitive 
functions". These functions include certain aspects of perception, memory, learning, but also language, reasoning, planning and decision making (...).Nevertheless, the results of the previous meta-analyses generally agree on a positive effect of acute exercise on cognition $[2,6,7]$. These results have been confirmed in the recent decade by meta-analyses [8-11] which revealed that acute exercise facilitates cognitive function, especially after physical activity.

In fact, a number of studies that have focused on young adults [12-14] or even on middle-aged adults $[15,16]$ have observed this improvement in cognitive performance following moderate intensity exercise. This effect is induced by the physiological arousal of exercise $[9,17]$. This has been demonstrated for several cognitive tasks such as simple or choice reaction times[18] or decision-making [19]. In the same way, Tomporowski (2003) concluded that the submaximal aerobic exercise of about 20-60 minutes has a positive effect on problem solving and complex decision making, while a prolonged exercise causes dehydration that compromises memory and information-processing functions [1].

Nonetheless, it is necessary to take into account several parameters to deal with the complexity of this relationship between acute exercise and cognitive performance[20] such as observed cognitive function on the one hand and the type and intensity of exercise chosen on the other.

The level of physical practice is an essential parameter to be taken in consideration when studying the interaction between physical exercise and cognition, specifically for executive functions. In this regard, several studies have analyzed differences in cognitive and perceptual skills among both expert and non-expert athletes[21,22]. The results of the previous studies agree on the superiority of experts over non-experts in terms of executive control of memory function [23], initial task learning [24], reaction time [25], decision-making [21] and perception of models $[26,27]$. This cognitive-perceptual superiority has been demonstrated in several areas such as team sports [28].

Gender differences have been shown to vary across cognitive domains, with some evidence of gender differences in brain activity during cognitive tasks [29] .However, the effect of gender is not well understood for central executive processes [30], inhibitory control [31] or treatment speed [32]. Although some studies have reported a slight male advantage in speed for reaction time simple and/or choice $[32,33]$.Others have not found this effect [34] .

To the best of our knowledge, nevertheless, how the interaction of several variables influences the cognitive profile remains to be explored. In addition, Voss et al. (2010) suggested that future studies of sport cognition should cross gender variables, a wide range of sports, and levels of expertise [35]. The objective of this study is to examine the impact of several variables related to the exercise on cognitive and psychomotor performance. In addition, the study is designed to consider the cross-effect gender, level of training and exercise on cognitive tasks namely visual perception, information processing and motor response. We hypothesized that subjects who exercise at higher levels would experience greater improvements in cognitive tasks after an acute aerobic exercise session. In addition, the size of the interaction across exercise effects, training level, and gender should vary with the type of cognitive task.

\section{Materials and Methods}

\subsection{Participants}

Differentiated by their level of expertise, eighty-eight females and male participants were classified into three groups. The first one is a novice group $(n=29)$ who are recruited from a high school of Casablanca included participants without handball experience, they just practice physical education two hours per week and their mean age was $20.07( \pm 3.4)$.The second group was the «advanced group» $(\mathrm{n}=30)$ recruited from a sport oriented university, at Hassan II University, Casablanca, included experienced of a three years training in Physical education and Sports and regularly practice their sports during and outside training. Mean age of the «advanced group» was $22.61( \pm 2.4)$ years. The third group was the «expert group» $(n=29)$ contained elite handball players playing in the first Moroccan Handball League, with a mean age of $24.53( \pm 3.6)$ years. All participants had normal vision and received written and oral information about the study. Before being tested every individual participant provided written consent. The study was approved by the local Ethics Committee and was performed in consideration of the 1964 Helsinki declaration.

Data from demographic and training questionnaire results are presented by mean and SD for each group in Table 1.

Table 1. Demographic and training characteristics of each group

\begin{tabular}{cccc}
\hline Sport level & Expert 29 & Advanced30 & Novice 29 \\
\hline Gender $(\mathrm{M} / \mathrm{F})$ & $(14 / 15)$ & $(15 / 15)$ & $(15 / 14)$ \\
Age & $24.53( \pm 3.6)$ & $22.61( \pm 2.4)$ & $20,07( \pm 3.4)$ \\
$\begin{array}{c}\text { Education } \\
\text { Years of }\end{array}$ & $10.12( \pm 2)$ & $15.23(0.4)$ & $12.07( \pm 0.2)$ \\
$\begin{array}{c}\text { training* } \\
\text { Practice per } \\
\text { week }\end{array}$ & $11.45( \pm 3.2)$ & $4.2( \pm 2.5)$ & $\mathrm{NA}$ \\
$\begin{array}{c}\text { Hour per } \\
\text { session }\end{array}$ & $3.14( \pm 0.51)$ & $3,09( \pm 0.8)$ & $2( \pm 0.2)$ \\
\hline
\end{tabular}

* The number of years of regular training in the club or at the university

\subsection{Research Design}

We opted to conduct an experimental study by adopting 
the Salomon protocol using a pre-test and a post-test in order to be able to evaluate the effect of exercise as an independent variable on cognitive performance. Therefore a battery of cognitive and psychomotor tests is performed collectively in the laboratory premises before and after one session of exercise. A verbal explanation of the experiment was given to all participants before starting, thereafter, to become familiar with the task, all participants solved two sequences of each cognitive and psychomotor tests in order to ensure understanding the task correctly. The tests are administered in the morning from $9 \mathrm{am}$ to $12 \mathrm{am}$. Also, the participant had to perform a ten minutes standardized warm-up first. This contained five minutes of moderate jogging, followed by three minutes of handball specific movements. The warm-up was concluded with two minutes of stretching. Afterward, each group were divided randomly by sex into two teams, to play a 20-minute non-stop Hand-Ball in the morning at 10:00 am in a cool and not very humid climate. We justify our choice of a handball match session of 20min duration by the conclusions of a review which was conducted of studies that assessed the effects of acute bouts of physical activity on adult's cognitive performance and whish concluded that the submaximal aerobic exercise of about 20-60 minutes has a positive effect on problem solving and complex decision making, while a prolonged exercise causes dehydration that compromises memory and information-processing functions [1].

\subsection{Measuring Instruments}

\subsubsection{Demographic and Training Questionnaire}

Before starting the experiment, the subjects completed a questionnaire in order to identify the demographic and training characteristics of the participants in each group. Participants were asked to answer questions about age, gender, and level of study, as well as their period of practice and training habits in terms of duration of training sessions and weekly recurrences, based on their sports experience over the past six months.

\subsubsection{WAIS-IV}

The Wechsler Adult Intelligence Scale (WAIS-IV, Wechsler, 2011) is the most advanced adult measure of cognitive ability, based on recent research in the area of cognitive neuroscience. It measures the information processing speed, short term memory, visual discrimination, visual perception, visual-motor coordination, visual scanning and attention, cognitive flexibility (Wechsler, 2003) reflecting the central integration capability of the central nervous system. It has been validated by several studies [36,37]. For our study we will use tests that represent the processing speed index that measures the speed of mental processes, using visual stimuli and requiring graphomotor skill

\subsubsection{Coding Test}

The Code subtest assesses a subject's ability to correctly and quickly scan a simple sequence containing visual information. The subjects receive a sheet of paper with numerical references corresponding to different symbols each time. The subject must write, in boxes, the symbol corresponding to each digit from $1-9$ presented randomly, as quickly as possible. The subject is also asked to write below each of the digits the corresponding symbol under good working conditions. The score will be recorded as the number of correct symbols drawn in $10 \mathrm{~min}$ and the number of errors made. The DSST test is very sensitive to psychostimulant factors.

\subsubsection{Search Symbol}

This test is designed to assess information processing speed and visual perception. The Symbol subtest tests the speed and accuracy of individuals in discriminating visual information. This index corresponds to the ability to quickly perform routine and automatic cognitive operations while maintaining concentration and being able to work under pressure. The test is presented in three columns, one with five symbols, a second with two isolated symbols, and finally the third with two boxes on which it is written "NO" and "YES". The participant indicates if one of the two symbols in the center column is among the 5 in the first column. If neither of the two symbols is among the five, he marks "NO". If one of them is found, he checks "YES", the aim being to give the maximum number of correct answers for 10 minutes. In fact, high scores require rapid and accurate processing of nonverbal visual information.

\subsubsection{Psychomotor Reaction Time Tests.}

In order to examine the reaction speed of choice, we used the Leeds Psychomotor Tester which is an instrument that measures several psychomotor parameters such as the critical flicker fusion threshold and choice reaction time (CRT) $[38,39]$, in our study we used this test in order to assesses the integrity of the sensorimotor system and is an accurate measure of psychomotor performance.

Participants were seated on a chair in front of a table on which the instrument of Leeds psychomotor tester was positioned. An example was presented to the participants, prior to the test trials for the pattern recall test. The task for the participants was to respond to a bright red color light that appears one of 6 led lights randomly by pressing the button where the red light shown. The buttons were equidistant from the resting position of the finger. Thus, for each participant we measured visual perception time (VPT) that occurs from the stimulus onset to the beginning of motor action, as well as the time of motor reaction time (MRT) that represents the time from onset of motor action to the end of performance. The total choice reaction time (TRT) corresponds to the sum of these two times (TRT= VPT + MRT). The reaction time recorded was the mean of 
five stimulus responses.

\subsection{Statistical Analysis}

Demographic items such as age, gender and level of education as well as training items such as sporting career, duration and frequency of sessions per week were compared among groups with one-way ANOVA.

The results achieved in the Coding test, Search Symbol test, visual perception time, motor response time and the choice reaction time are presented by mean and standard deviation. These variables are analyzed by the multivariate variance of MANOVA to examine the multivariate effects of exercise, training level and gender on cognitive perception variation and psychomotor performance in confirmed athletes and high school athletes. The significance level is set at .05 . We have decided to use the MANOVA test in order to determine whether the factors analyzed have a significant effect on the dependent variables. We also used it to identify the effect of interactions between the dependent and independent variables.

We also performed post-hoc analyses by examining the effect of size through the calculation of the square-square index in order to represent the proportions of the variance of the dependent variable explained by the independent variable. The interpretation of this index, which varies between 0 and 1 , goes from a small size effect, a medium size effect and a large size effect if the index is respectively $0.01,0.06$ and 0.14 and more according to the markers that were developed by Cohen (1988).

\section{Results}

The results of the cognitive test of the study are reported as means $\pm \mathrm{SD}$ respectively in the figure $1,2,3,4$ and 5 .

\subsection{Variance of Cognitive and Psychomotor Performance}

\subsubsection{Exercise Effect}

Following the exercise, as shown in figures 1 and 2, respectively, for the three groups, the results show highly significant increase in coding-decoding test $(\mathrm{F}=53,05$, $\mathrm{p}=.000, \eta 2=.603$; novice $20.22 \%$ more than advanced $13.91 \%$ and more than expert $6.59 \%$ ), and Search Symbol test $(\mathrm{F}=27,97, \mathrm{p}=.000, \eta 2=.444$; respectively novice $33.12 \%$, advanced $26.35 \%$ and expert $24.34 \%$ ), whereas, errors showed no significant difference $(F=1,26, p=.268$, $\eta 2=.035$ ).

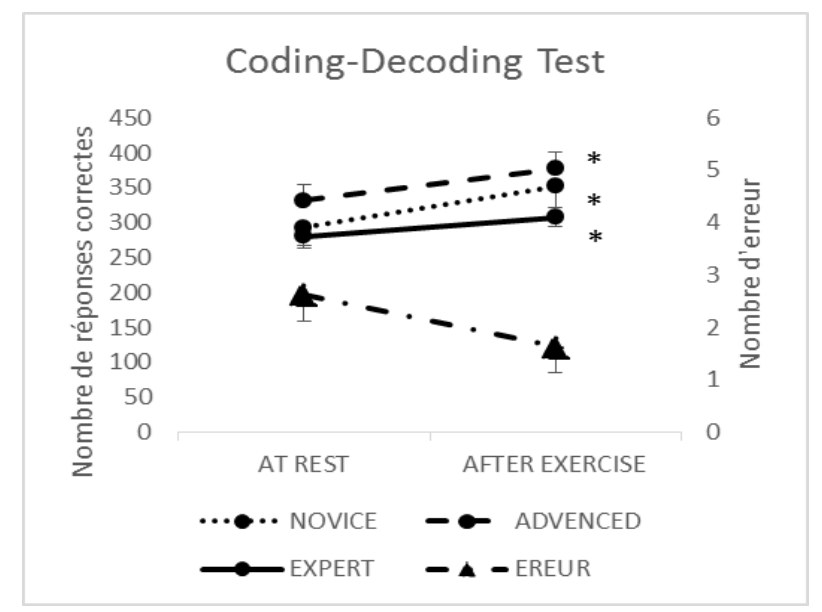

Figure 1. Mean test scores at rest and after exercise for each group for Coding-Decoding test .*Differs significantly after exercise

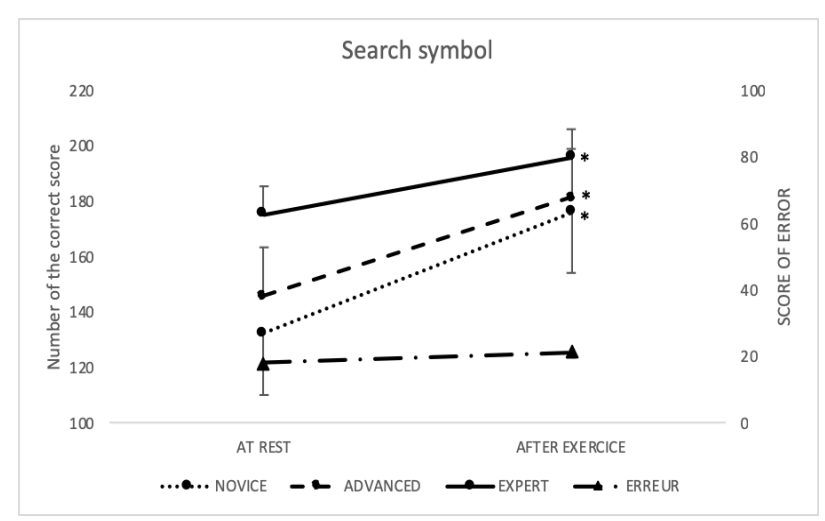

Figure 2. Mean test scores at rest and after exercise for each group for Search Symbol test. . Differs significantly after exercise

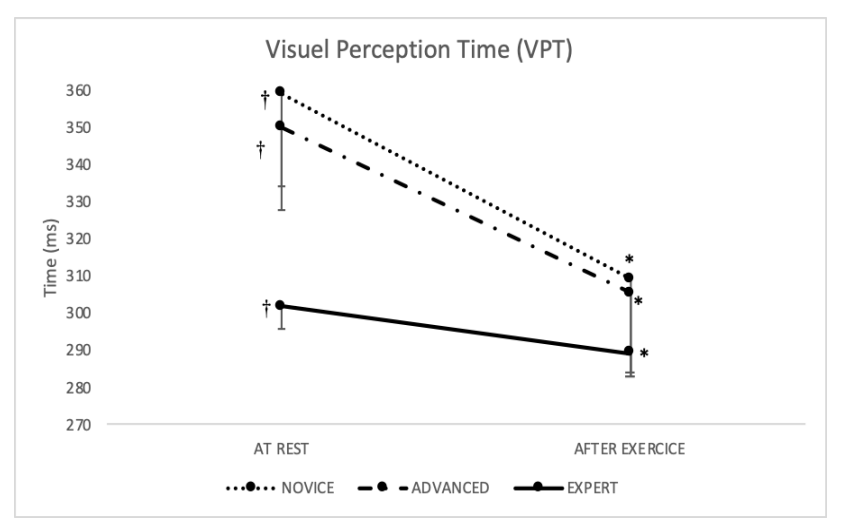

$*$ Differs significantly after exercise.$\dagger$ significant difference under the group effect

Figure 3. Mean test scores at rest and after exercise for Visuel Perception Time (VPT). 


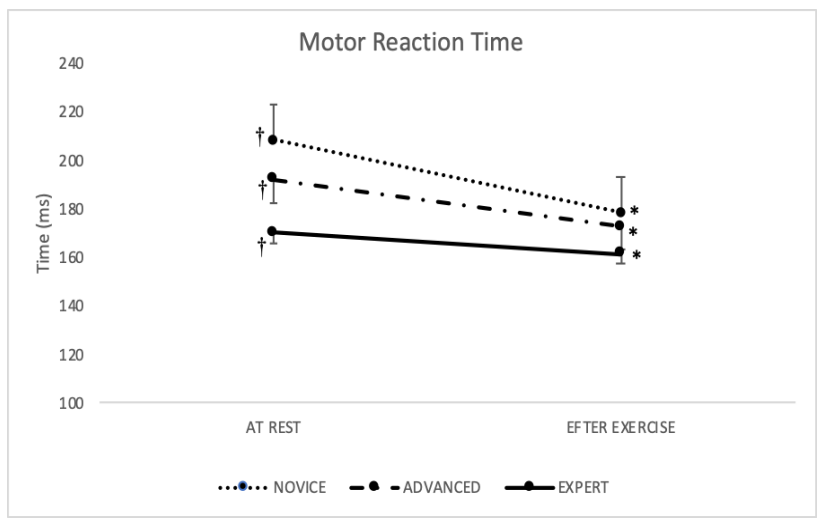

Figure 4. Mean test scores at rest and after exercise for Motor Reaction Time ( MRT ). * Differs significantly after exercise. $\dagger$ significant difference under the group effect

For the variables of psychomotor test, respectively in figures 3,4 and 5 , the results analyzed by MANOVA reached an overall significant decrease, including visual perception time $(\mathrm{F}=5.01, \mathrm{p}=.032, \eta 2=.145$; novice $13.88 \%$ more than advanced $12.77 \%$ and then expert $4.22 \%$ ), motor reaction time $(\mathrm{F}=9.34, \mathrm{p}=.004, \eta 2=.445$; respectively, novice $14.34 \%$, advanced $9.94 \%$ and expert $17.83 \%$ ), and choice reaction time $(\mathrm{F}=12.42, \mathrm{p}=.001, \eta 2=.590$; novice $2.78 \%$ more than advanced $10.49 \%$ and more than expert $6.77 \%)$.

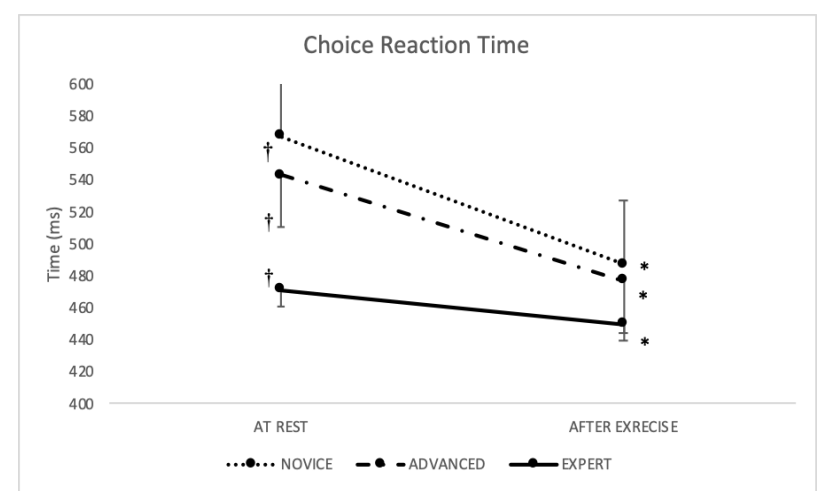

* Differs significantly after exercise. $\uparrow$ significant difference under the group effect

Figure 5. Mean test scores at rest and after exercise for Total Choice Reaction Time ( TRT ).

\subsubsection{Group effect}

Under group effect, no group difference was found on cognitive test; $\mathrm{CD}(\mathrm{F}=19,79, \mathrm{p}=.106, \eta 2=.606)$ and $\mathrm{SS}$ $(\mathrm{F}=16.21, \mathrm{p}=.9, \eta 2=.067)$. The ANOVA on psychomotor performance showed significant differences among groups on visual perception time $(\mathrm{F}=5,58, \mathrm{p}=.009, \eta 2=.379)$, motor reaction time $(\mathrm{F}=9.34, \mathrm{p}=.006, \eta 2=.497)$ and choice reaction time $(\mathrm{F}=5.96, \mathrm{p}=.000, \eta 2=.704)$. Expert group appeared to have better psychomotor performance than advanced and then novice group, which can be seen from results at rest with the lower time of perception, motor response and the choice reaction.

\subsubsection{Gender effect}

Table 2. Cross effects of exercise, group and gen der on variation of cognitive perception and psychomotor performance.

\begin{tabular}{cccccccc}
\hline \multirow{2}{*}{$\begin{array}{c}\text { Variable } \\
\text { dépendante }\end{array}$} & \multicolumn{2}{c}{ Ex. ${ }^{*} \mathrm{G}$} & \multicolumn{2}{c}{$\begin{array}{c}\text { Ex.* } \\
\text { Sexe }\end{array}$} & \multicolumn{2}{c}{$\begin{array}{c}\text { Groupe } \\
\text { Sexe }\end{array}$} \\
\cline { 2 - 8 } & $\mathrm{p}$ & Eta & & & $\mathrm{p}$ & Eta \\
\hline $\mathrm{CD}$ & 0.000 & 0.417 & 0.781 & 0.002 & 0.604 & 0.17 \\
$\mathrm{SS}$ & 0.000 & 0.461 & 0.435 & 0.018 & 0.615 & 0.007 \\
$\mathrm{VPT}$ & 0.024 & 0.238 & 0.243 & 0.039 & 0.367 & 0.023 \\
TRT & 0.02 & 0.146 & 0.034 & 0.123 & 0.206 & 0.064 \\
MRT. & 0.026 & 0.034 & 0.005 & 0.121 & 0.342 & 0.026 \\
\hline
\end{tabular}

CD : Coding-Decoding, SS : Search Symbol, VPT : Visuel Perception Time, TRT : Total Reaction Time, MRT : Motor Reaction Time

The analyses of gender revealed, none reached significance, including ${ }^{\mathrm{C}} \mathrm{CD}(\mathrm{p}=.604, \eta 2=.17)$, SS $(p=.615, \eta 2=.007)$, VPT $(p=.367, \eta 2=.023)$. On the other hand, we identified significant differences between MRT $(\mathrm{p}=.001, \eta 2=.026)$ and CRT $(\mathrm{p}=.000, \eta 2=.064)$. Indeed, girls react $10.35 \%$ slower in CRT and $19.23 \%$ in MRT than boys before the exercise.

Our results were also subjected to three-way mixed design ANOVA. (Table. 2)

\subsection{Interaction Exercise, Gender}

The results of the interaction between gender and exercise show no significant difference in the speed of information processing which can be seen from results of $\mathrm{CD}(\mathrm{p}=.106)$ and SS $(\mathrm{p}=.9)$. Moreover, we did not observe any significant differences in visual perception $(\mathrm{p}=.243)$. However, the motor reaction time and choice reaction time were significantly different among gender $(\mathrm{F}=4.89, \mathrm{p}=$ $0.034, \eta 2=0.123$ and $\mathrm{F}=4.80, \mathrm{p}=0.005, \eta 2=0.121$, respectively). Post hoc comparison showed that females are longer than males with $10.09 \%$ on motor reaction time and $6.57 \%$ on choice reaction time.

\section{Interaction exercise, group}

Overall, the expert group had significantly better performance than advanced group and then novice group both on Speed of information processing with $(\mathrm{P}=.000, \eta 2$ $=0.417)$ for $\mathrm{CD},(\mathrm{p}=.000, \eta 2=.461)$ for $\mathrm{SS}$, and on visual perception time with $(\mathrm{p}=.024, \eta 2=0.238)$. But a post hoc comparison showed that the novice group, remain having the better amelioration than advanced group and then expert following the exercise

\section{Discussion}

The aim of the present study was to examine how the interaction of different variables may be associated with changes in some cognitive and psychomotor aspects. Specifically, we aim to explore the relationship between the cross effect of different level of training, gender and 
exercise on information processing, visual perception and choice reaction time. As expected, expert athletes outperformed advanced athletes and novices in many aspects: we found that the expert group has a higher performance and the novice group has the lowest, on visual perception, information processing and choice reaction. These evidences suggesting Handball activity as a dynamic team sport place high demands on visuospatial and other cognitive skills, and in turn, this will determine the behavior and outcome of the performance. Further, in our study expert group not only have highest performance than advanced and novice on such cognitive abilities but also the performance was accentuated by the exercise. Moreover, novice group showed better enhancement in all the parameters observed during this study. In addition, under cross effect, gender differences mainly within the expert group with regard to tasks requiring perceptual and motor speed are minimized. Overall, a higher level of training corresponds to a higher level in some cognitive abilities, although novices have a greater range of improvement following the exercise. Also, the combination of the level of training and exercise attenuates differences on some sensorimotor speed performance between the two sexes.

In general, our results are consistent with several study [40-42] which have revealed differences between experts and novices, and demonstrated on some meta-analyses, by the way majority of them corroborate that expertise in sport was related to high levels of performance on measures of processing speed and visual attention, [35]. In this sense, recently, the results found by various studies on footballers[43], tenis-mans [44] and baseball players [45] agree on the superiority in sensorimotor speed of experts compared to amateur or novice athletes. Ursula Debarnot and her co-authors (2014), claim that experts become able to handle with a large amount of information required by the task by using fast and efficient automatic sequences [46]. This neural plasticity allows the experts to achieve maximum performance. In the same line of research, with the progress of neurophysiology, laboratory-based studies comparing expert with novice have attributed a greater neural efficiency to the expert athletes with a smaller motor related cortical potentials [47-49], shorter latency [50] and smaller peak amplitude [51] of visual evoked potentials in athletes.

However, in our study we did not replicate the superiority of expert group on coding decoding test compared to other groups. This inconsistency may be related to the level of education. In fact, elite athletes in Morocco do not usually attend college, there was a significant difference in education between the expert group and recreationally active groups. It would have been ideal if we selected athletes and controls with the same amount of formal education.

The results of the present study demonstrate that in spite of the different levels of baseline cognition, all groups had significant improvement in cognitive domains with regard to information processing speed and visual perception. Nevertheless, exercise has a positive but selective effect on certain cognitive functions [52]. This is consistent with several meta-analyses, which confirm different effect following a single bout of exercise on neuropsychological skills and mental functions $[9,8,11]$, among others in late adulthood with small to moderate sized effects [53] and with the largest effect sizes for indices of executive function [54] .This finding can be explained by different neurophysiological mechanisms involving activation process of the central nervous system and neurotrophic factors released during exercise that act on brain plasticity and thus contribute to improvements in processing speed, attention and executive function $[53,55,56]$.

Likewise, our results showed differences in neuropsychological functioning of males and females under the cross effect of exercise and gender in tasks that require a certain visio-spatial speed such as CRT, especially in amateur groups. These differences, among other things, can be explained by culture and education attribution [57,58]. We have observed a reduction in these differences at the group of expert's levels due to practice and training that appear to reduce gender differences in spatial ability $[59,60]$. This finding is also consistent with the conclusions of the study done by Ryan et al. in 2004, which affirmed the possibility of reducing perceptual and motor differences between experienced male and female athletes who are participating in similar learning and training programs [61].

\section{Conclusions}

The results of the cross effects of gender, exercise and level of expertise on the cognitive profile highlight the relationship between sport and cognition. The enhancement of cognitive performance can be stimulated by exercise despite the gender and level of training. The leeway of improvement is greater among recreational, while at the expert level, it is females who benefit more from the advantage provided by their sport training.

Ultimately, on the one hand, for the mass, school and university training programs may exploit physical and sports activity to a greater extent as a means of optimizing learning, which mainly requires the cognitive faculties in question. On the other hand, for the sporting elite, trainers could be enlightened in order to be able to maximize the performance of future athletes, especially female athletes, particularly in tasks that require greater perceptual and motor skills.

Other researches should experiment with more complex research protocols that include several intermediate parameters such as age, type of exercise, different sports, different cognitive tasks in order to evaluate more closely this complex relationship between sport and cognition. 


\section{Conflict of Interest Statement}

The authors declare that the research was conducted in the absence of any commercial or financial relationships that could be construed as a potential conflict of interest.

\section{REFERENCES}

[1] Tomporowski PD. Effects of acute bouts of exercise on cognition. Acta Psychologica 2003;112:297-324. https://d oi.org/10.1016/S0001-6918(02)00134-8.

[2] Brisswalter J, Collardeau M, Ren?? A. Effects of Acute Physical Exercise Characteristics on Cognitive Performance: Sports Medicine 2002;32:555-66. https://doi.org/10.2165/0 0007256-200232090-00002.

[3] Davranche K, McMorris T. Specific effects of acute moderate exercise on cognitive control. Brain and Cognition 2009;69:565-70.

https://doi.org/10.1016/j.bandc.2008.12.001.

[4] Del Giorno JM, Hall EE, O’Leary KC, Bixby WR, Miller PC Cognitive Function During Acute Exercise: A Test of the Transient Hypofrontality Theory. Journal of Sport and Exercise Psychology 2010;32:312-23. https://doi.org/10.11 23/jsep.32.3.312.

[5] Said Lotfi , Imane Elmoutaraji, Mohammed Talbi , "Effect of Physical Exercise and Gender on Information Processing and Choice Reaction Time of University Students," International Journal of Human Movement and Sports Sciences, Vol. 8, No. 1, pp. 37 - 42, 2020. DOI: 10.13189/saj.2020.080105.

[6] Mcmorris T, Graydon J. The effect of incremental exercise on cognitive performance. International Journal of Sport Psychology 2000;31.

[7] Tomporowski PD. Cognitive and behavioral responses to acute exercise in youths: A review. Pediatr Exerc Sci 2003;15:348-59. https://doi.org/10.1123/pes.15.4.348.

[8] Chang YK, Labban JD, Gapin JI, Etnier JL. The effects of acute exercise on cognitive performance: A meta-analysis. Brain Research 2012;1453:87-101. https://doi.org/10.1016/ j.brainres.2012.02.068.

[9] Lotfi S., Madani M., Tazi A., Boumahmaza M., Talbi M. Variation of cognitive functions and glycemia during physical exercise in Ramadan fasting. Revue neurologique. 2010 Doi : 10.1016/j.neurol.2010.01.016

[10] McMorris T, Sproule J, Turner A, Hale BJ. Acute, intermediate intensity exercise, and speed and accuracy in working memory tasks: A meta-analytical comparison of effects. Physiology \& Behavior 2011;102:421-8. https://doi.org/10.1016/j.physbeh.2010.12.007.

[11] Lotfi, Said \& Madani, Mohamed \& Abassi, A \& Tazi, A \& Boumahmaza, M \& Talbi, Mohammed. (2010). CNS Activation, Reaction Time, Blood Pressure and Heart Rate Variation During Ramadan Intermittent Fasting and Exercise. World J Sport Sci. 3.

[12] Chen A-G, Yan J, Yin H-C, Pan C-Y, Chang Y-K. Effects of acute aerobic exercise on multiple aspects of executive function in preadolescent children. Psychology of Sport and Exercise 2014;15:627-36. https://doi.org/10.1016/j.psychsp ort.2014.06.004.

[13] Lambourne K, Audiffren M, Tomporowski PD. Effects of Acute Exercise on Sensory and Executive Processing Tasks: Medicine \& Science in Sports \& Exercise 2010;42:1396402. https://doi.org/10.1249/MSS.0b013e3181cbee11.

[14] Pesce C, Crova C, Cereatti L, Casella R, Bellucci M. Physical activity and mental performance in preadolescents: Effects of acute exercise on free-recall memory. Mental Health and Physical Activity 2009;2:16-22. https://doi.org/10.1016/j.mhpa.2009.02.001.

[15] Chang Y-K, Ku P-W, Tomporowski PD, Chen F-T, Huang C-C. Effects of Acute Resistance Exercise on Late-Middle-Age Adults' Goal Planning: Medicine \& Science in Sports \& Exercise 2012;44:1773-9. https://doi.org/10.1249/MSS.0b013e3182574e0b.

[16] Chang Y-K, Tsai C-L, Huang C-C, Wang C-C, Chu I-H Effects of acute resistance exercise on cognition in late middle-aged adults: General or specific cognitive improvement? Journal of Science and Medicine in Sport 2014;17:51-5. https://doi.org/10.1016/j.jsams.2013.02.007.

[17] Pesce C, Audiffren M. Does acute exercise switch off switch costs? A study with younger and older athletes. J Sport Exerc Psychol 2011;33:609-26.

[18] Pesce C, Tessitore A, Casella R, Pirritano M, Capranica L. Focusing of visual attention at rest and during physical exercise in soccer players. Journal of Sports Sciences 2007;25:1259-70.

https://doi.org/10.1080/02640410601040085.

[19] Brisswalter J, Collardeau M, René A. Effects of Acute Physical Exercise Characteristics on Cognitive Performance. Sports Med 2002;32:555-66. https://doi.org/10.2165/00007 256-200232090-00002.

[20] Sibley BA, Beilock SL. Exercise and Working Memory: An Individual Differences Investigation. Journal of Sport and Exercise Psychology 2007;29:783-91. https://doi.org/10.11 23/jsep.29.6.783.

[21] Mann DTY, Williams AM, Ward P, Janelle CM. Perceptual-cognitive expertise in sport: a meta-analysis. J Sport Exerc Psychol 2007;29:457-78. https://doi.org/10.11 23/jsep.29.4.457.

[22] Starkes, J., Helsen, W. F., \& Jack, R. . Expert performance in sport and dance. Handbook of sport psychology. In R. N. Singer, H. A. Hausenblas, C. M. Janelle (Eds.), New York: Wiley.: 2001, p. 174-201.

[23] Chaddock L, Hillman CH, Buck SM, Cohen NJ. Aerobic Fitness and Executive Control of Relational Memory in Preadolescent Children: Medicine \& Science in Sports \& Exercise 2011;43:344-9. https://doi.org/10.1249/MSS.0b01 3e3181e9af48.

[24] Raine LB, Lee HK, Saliba BJ, Chaddock-Heyman L, Hillman $\mathrm{CH}$, Kramer AF. The Influence of Childhood Aerobic Fitness on Learning and Memory. PLoS ONE 2013;8:e72666. https://doi.org/10.1371/journal.pone.0072666.

[25] Luque-Casado A, Zabala M, Morales E, Mateo-March M, Sanabria D. Cognitive Performance and Heart Rate 
Variability: The Influence of Fitness Level. PLOS ONE 2013;8:e56935.

https://doi.org/10.1371/journal.pone.0056935.

[26] Abernethy B, Baker J, Côté J. Transfer of Pattern Recall Skills May Contribute to the Development of Sport Expertise. Applied Cognitive Psychology 2005;19:705-18. https://doi.org/10.1002/acp.1102.

[27] Williams, A. M.,, Burwitz, K. Advance cue utilization in soccer. Science and football. In T. Reilly, J. Clarys, A. Stibbe, London, GB: E\&FN Spoon.: 1993, p. 239-243.

[28] Schapschröer M, Baker J, Schorer J. Effects of domain-specific exercise load on speed and accuracy of a domain-specific perceptual-cognitive task. Human Movement Science 2016;48:121-31. https://doi.org/10.101 6/j.humov.2016.05.001.

[29] Bell EC, Willson MC, Wilman AH, Dave S, Silverstone PH. Males and females differ in brain activation during cognitive tasks. NeuroImage 2006;30:529-38. https://doi.org/10.1016 /j.neuroimage.2005.09.049.

[30] McEwen BS. The neurobiology of stress: from serendipity to clinical relevance. Brain Res 2000;886:172-89.

[31] Macleod C. Half a Century of Research on the Stroop Effect - an Integrative Review. Psychol Bull 1991;109:163-203. https://doi.org/10.1037/0033-2909.109.2.163.

[32] Deary IJ, Der G. Reaction Time, Age, and Cognitive Ability: Longitudinal Findings from Age 16 to 63 Years in Representative Population Samples. Aging,

Neuropsychology, and Cognition 2005;12:187-215. https:// doi.org/10.1080/13825580590969235.

[33] Der G, J Deary I. Age and sex differences in reaction time in adulthood: Results from the United Kingdom Health and Lifestyle Survey. Psychology and Aging 2006;21:62-73. https://doi.org/10.1037/0882-7974.21.1.62.

[34] Meinz EJ, Salthouse TA. The effects of age and experience on memory for visually presented music. J Gerontol B Psychol Sci Soc Sci 1998;53:P60-69.

[35] Voss MW, Kramer AF, Basak C, Prakash RS, Roberts B. Are expert athletes 'expert' in the cognitive laboratory? A meta-analytic review of cognition and sport expertise. Applied Cognitive Psychology 2010;24:812-26. https://doi.org/10.1002/acp.1588.

[36] Benson, N., Hulac, D. M., \& Kranzler, J. H. (2010). Independent examination of the Wechsler Adult Intelligence Scale-Fourth Edition (WAIS-IV): What does the WAIS-IV measure? Psychological Assessment, 22(1), 121-130. https://doi.org/10.1037/a001776

[37] Weiss LG, Keith TZ, Zhu J, Chen H. WAIS-IV and Clinical Validation of the Four- and Five-Factor Interpretative Approaches. Journal of Psychoeducational Assessment. 2013;31(2):94-113. doi:10.1177/0734282913478030

[38] Hindmarch I. Psychomotor function and psychoactive drugs. 1980. Br J Clin Pharmacol 2004;58:S720-740; discussion S741-743.

https://doi.org/10.1111/j.1365-2125.2004.02279.x.

[39] Strauss P of PE, Strauss E, Sherman N and AAPD of P and CNEMS, Sherman EMS, Spreen O. A Compendium of Neuropsychological Tests: Administration, Norms, and
Commentary. Oxford University Press; 2006.

[40] Nakata H, Yoshie M, Miura A, Kudo K. Characteristics of the athletes' brain: Evidence from neurophysiology and neuroimaging. Brain Research Reviews 2010;62:197-211. https://doi.org/10.1016/j.brainresrev.2009.11.006.

[41] Perrey S, Besson P. Studying brain activity in sports performance: Contributions and issues. Prog Brain Res 2018;240:247-67.

https://doi.org/10.1016/bs.pbr.2018.07.004.

[42] Smith DM. Neurophysiology of action anticipation in athletes: A systematic review. Neuroscience \& Biobehavioral Reviews 2016;60:115-20. https://doi.org/10. 1016/j.neubiorev.2015.11.007.

[43] Verburgh L, Scherder EJA, Lange PAM van, Oosterlaan J. Executive Functioning in Highly Talented Soccer Players. PLOS ONE 2014;9:e91254.https://doi.org/10.1371/journal. pone.0091254.

[44] Overney LS, Blanke O, Herzog MH. Enhanced Temporal but Not Attentional Processing in Expert Tennis Players. PLOS ONE 2008;3:e2380.https://doi.org/10.1371/journal.p one.0002380.

[45] Burris K, Vittetoe K, Ramger B, Suresh S, Tokdar ST, Reiter JP, et al. Sensorimotor abilities predict on-field performance in professional baseball. Sci Rep 2018;8:1-9. https://doi.org/10.1038/s41598-017-18565-7.

[46] Debarnot U, Sperduti M, Di Rienzo F, Guillot A. Experts bodies, experts minds: How physical and mental training shape the brain. Frontiers in Human Neuroscience 2014;8. https://doi.org/10.3389/fnhum.2014.00280.

[47] Del Percio C, Rossini PM, Marzano N, Iacoboni M, Infarinato F, Aschieri P, et al. Is there a "neural efficiency" in athletes? A high-resolution EEG study. NeuroImage 2008;42:1544-53. https://doi.org/10.1016/j.neuroimage.2008.05.061.

[48] Di Russo F, Pitzalis S, Aprile T, Spinelli D. Effect of Practice on Brain Activity: An Investigation in Top-Level Rifle Shooters: Medicine \& Science in Sports \& Exercise 2005;37:1586-93.

https://doi.org/10.1249/01.mss.0000177458.71676.0d.

[49] Kita Y, Mori A, Nara M. Two types of movement-related cortical potentials preceding wrist extension in humans: Neuroreport 2001;12:2221-5. https://doi.org/10.1097/0000 1756-200107200-00035.

[50] Delpont E, Dolisi C, Suisse G, Bodino G, Gastaud M. Visual Evoked Potentials: Differences Related to Physical Activity. Int J Sports Med 1991;12:293-8.https://doi.org/10.1055/s-2 007-1024684.

[51] Del Percio C, Brancucci A, Vecchio F, Marzano N, Pirritano $\mathrm{M}$, Meccariello $\mathrm{E}$, et al. Visual event-related potentials in elite and amateur athletes. Brain Research Bulletin 2007;74:104-12. https://doi.org/10.1016/j.brainresbull.2007.05.011.

[52] Lotfi S, Karyouh S. Effect of Physical Exercise on Neurocognitive Performances in University Students 2016;3:7.

[53] Smith PJ, Blumenthal JA, Hoffman BM, Cooper H, Strauman TA, Welsh-Bohmer K, et al. Aerobic exercise and 
neurocognitive performance: a meta-analytic review of randomized controlled trials. Psychosom Med 2010;72:23952. https://doi.org/10.1097/PSY.0b013e3181d14633.

[54] Colcombe S, Kramer AF. Fitness effects on the cognitive function of older adults: A meta-analytic study. Psychol Sci 2003; 14:125-30.

https://doi.org/10.1111/1467-9280.t01-1-01430.

[55] El Jaziz A, Lotfi S, Ahami AOT. Interrelationship of physical exercise, perceptual discrimination and academic achievement variables in high school students. Ann Ig. 2020 Sep-Oct;32(5):528-540. doi: 10.7416/ai.2020.2373. PMID: 32744584 .

[56] Voelcker-Rehage C, Niemann C. Structural and functional brain changes related to different types of physical activity across the life span. Neuroscience and Biobehavioral Reviews 2013;37:2268-95. https://doi.org/10.1016/j.neubio rev.2013.01.028.
[57] Caplan PJ, Crawford M, Hyde JS, Richardson JTE. Gender Differences in Human Cognition 2012:1-192. https://doi.or g/10.1093/acprof:oso/9780195112917.001.0001.

[58] Kimura D. Sex and cognition. Cambridge, MA, US: The MIT Press; 1999.

[59] Chance JE, Goldstein AG. Internal-external control of reinforcement and embedded-figures performance. Perception \& Psychophysics 1971;9:33-4. https://doi.org/1 $0.3758 / \mathrm{BF} 03213024$

[60] Connor,J.M., Serbin,L.A, Schak- man, M. Sex differences in children's responses to training in a visual-spatial test. DevPsychol 1977:293-294.

[61] Ryan J, Atkinson T, Dunham K. Sports-Related and Gender Differences on Neuropsychological Measures of Frontal Lobe Functioning. Clinical Journal of Sport Medicine 2004; $14: 18-24$ 